\begin{tabular}{|c|c|c|c|c|}
\hline $\begin{array}{c}\text { Jurnal Penelitian \& } \\
\text { PPM }\end{array}$ & ISSN: 2442-448X & Vol 5, No: 1 & Hal: $1-110$ & April 2018 \\
\hline
\end{tabular}

\title{
PEKERJAAN SOSIAL: BEKERJA BERSAMA ORANG DENGAN GANGGUAN BIPOLAR
}

\author{
Oleh: \\ Meilanny Budiarti S. ${ }^{1}$, Budhi Wibhawa ${ }^{2}$, Ishartono ${ }^{3}$, Franzeska Venty WD ${ }^{4}$ \\ 1. Dosen IImu Kesejahteraan Sosial, Fakultas IImu Sosial Dan IImu Politik, Universitas Padjadjaran \\ 2. Dosen IImu Kesejahteraan Sosial, Fakultas IImu Sosial Dan IImu Politik, Universitas Padjadjaran \\ 3. Dosen IImu Kesejahteraan Sosial, Fakultas IImu Sosial Dan IImu Politik, Universitas Padjadjaran \\ 4. Mahasiswa Program Studi Sarjana (S1) Ilmu Kesejahteraan Sosial, Fakultas IImu Sosial Dan Ilmu Politik, \\ Universitas Padjadjaran \\ meilannybudiarti13@gmail.com,budhiwibhawa@gmail.com_kesosish@gmail.com,franzeskaven07@gmail.com
}

\begin{abstract}
ABSTRAK
Penderita gangguan bipolar mengalami kondisi suasana hati yang berubah secara signifikan. Terdapat dua fase yang dialami oleh penderita, yaitu fase mania dengan perasaan gembira yang berlebihan, dan fase depresi dengan perasaan sedih yang juga berlebihan, bahkan dapat menimbulkan keinginan bunuh diri. Penyebab gangguan bipolar dapat dilatarbelakangi oleh faktor genetika, biologis, maupun lingkungan. Penanganannya tidak lepas dari pengobatan dan perawatan secara medis, perawatan mental dan dukungan secara sosial dengan melibatkan psikiater, perawat, dan pekerja sosial dalam satu tim yang terlibat dan bekerja bersama-sama dengan penderita untuk kesembuhannya. Pada konteks pekerjaan sosial, profesi pekerja sosial menawarkan dukungan kepada individu yang menderita gangguan bipolar serta dukungan keluarga yang dapat membantu keberlangsungan proses penyembuhannya. Pekerja sosial juga dapat memberikan layanan berupa pertemuan rutin, baik untuk melakukan konseling maupun pemecahan masalah dan gejala kekambuhannya, dan melalui penugasan dalam kelompok yang dihadiri oleh penderita, layanan manajemen kasus untuk mengakomodasi kebutuhan dan bantuan klien, bahkan memberikan layanan dukungan kepada keluarga untuk membantu mereka dalam masa penyembuhannya.
\end{abstract}

Kata kunci: gangguan bipolar, kondisi suasana hati, manajemen kasus, pekerjaan sosial.

\section{ABSTRACT}

Patients with bipolar disorder experience mood conditions change significantly. There are two phases experienced by the patient, the manic phase with excessive excitement, and a phase of depression with feelings of sadness were also excessive, it can even lead to suicidal thoughts. Causes of bipolar disorder may be motivated by factors of genetic, biological, and environmental. Handling can not be separated from the treatment and medical care, treatment and mentally care, and social support by involving psychiatrists, nurses, and social workers into the teams involved and work together with the patient to recovery. In the context of social work, professional social workers offer support to individuals suffering from bipolar disorder and family support that could help the sustainability of the healing process. The social worker can also provide services such as regular meetings, both for counseling as well as solving the problem and the symptoms of recurrence, and through the assignment in the group, which was attended by patients, case management services to accommodate the needs and help clients, even providing support services to families to help them in a period of recovery.

Keywords: bipolar disorder, mood conditions, case management, social work.

\section{Pendahuluan}

Pada kehidupan manusia, umumnya tidak lepas dari suasana hati yang dialami setiap harinya, entah suasana hati yang baik (mood high) maupun suasana hati yang buruk (mood low). Kondisi tersebut menjadi suatu hal yang wajar, namun akan berbeda dengan kondisi yang dialami oleh penderita gangguan bipolar. Gangguan bipolar merupakan salah satu bentuk gangguan yang terjadi pada kondisi suasana hati yang berubah-ubah secara signifikan dan ekstrem pada penderitanya. Seperti yang disebutkan oleh Ryan dan Jacki (2004: 331), bahwa orang dengan gangguan bipolar mengalami fluktuasi luas dalam 
suasana hatinya, baik pada suasana hati yang begitu 'baik' atau suasana hati yang begitu 'buruk' pada dirinya. Hal tersebut terjadi karena kondisi suasana hati penderitanya dapat berganti secara tiba-tiba antara kondisi baik atau bahagia (mania) dan buruk atau kesedihan (depresi), dan berada pada tingkat yang berlebihan dari batas kewajaran.

Keadaan yang terjadi pada penderita bipolar juga disampaikan oleh Samosir (2015), seorang psikiater, yang menyatakan bahwa bipolar secara sederhana merupakan gangguan suasana perasaan yang dicirikan dengan adanya dua kutub ekstrem emosi. Lebih lanjut disampaikan olehnya pada cuplikan berikut ini:

"Emosi manusia itu ada dua kutub, gembira dan sedih. Keduanya ada batasnya. Orang dengan bipolar, batasnya berlebihan. Saat sedih, ia bisa berlebihan, begitu pula dengan gembira juga berlebihan. Amplitudo emosinya sangat tinggi," (Samosir, 2015).

Dua kutub emosi itu berlawanan dan dapat berganti secara tiba-tiba tanpa diketahui kapan waktu 'kambuhnya'. Pada mania (manic) atau emosi gembira yang berlebihan dapat terjadi ketika seorang penderita gangguan bipolar menjadi sangat bersemangat, hiperaktif, dan antusias, sedangkan pada depresi atau emosi sedih yang berlebihan dapat terjadi ketika penderitanya menjadi sangat pesimis, putus asa, gelisah, tekanan pikiran, tidak berdaya, bahkan dapat muncul keinginan untuk melakukan bunuh diri.

Kondisi yang dialami oleh penderita gangguan bipolar disebabkan oleh banyak faktor, baik faktor biologis pada diri penderita maupun faktor di lingkungan sekitarnya yang mempengaruhi kondisi individu dengan gangguan bipolar. Seperti yang dinyatakan oleh Watts dan Markham (dalam Smith 2011: 335), bahwa kondisi bipolar juga dipengaruhi oleh faktor biologis dan lingkungan, tetapi genetika memainkan peran yang lebih besar daripada yang mereka lakukan dengan depresi unipolar. Berdasarkan pandangan tersebut, faktor genetika dapat terjadi apabila seorang anak lahir dari salah satu atau kedua orang tua yang menderita gangguan bipolar, sehingga memiliki resiko untuk mengalami gangguan yang sama.

Faktor lingkungan, seperti keluarga, dapat menjadi salah satu faktor yang kuat dalam mempengaruhi kondisi individu dengan gangguan bipolar. Adanya anggota keluarga yang mengungkapkan atau mengekspresikan emosi terhadap anggota lain di keluarganya yang menderita gangguan bipolar merupakan faktor dari interaksi yang dapat menyebabkan tingkat kekambuhan yang lebih tinggi bagi individu dengan gangguan bipolar yang disebabkan oleh pengaruh ungkapan emosi keluarganya. Dengan demikian, penanganan dalam penyembuhan gangguan bipolar dapat dilakukan selain dengan pengobatan menggunakan obat-obatan ataupun perawatan terapi tertentu, dapat pula dilakukan dengan memberikan dukungan soial dari keluarga.

Namun demikian, gangguan bipolar sering tidak diketahui dan salah diagnosis, bahkan bila terdiagnosa pun sering tidak terobati dengan adekuat (Evans, 2000; Tohen \& Angst, 2002; Toni et.al, 2000). Diagnosis gangguan bipolar sulit dibuat karena gangguan bipolar bertumpang tindih dengan gangguan psikiatrik yang lain, yaitu skizofrenia dan skizoafektif.

Dengan demikian, terapi yang komprehensif diperlukan oleh orang dengan gangguan bipolar untuk mencapai kembali fungsinya semula, yaitu meliputi farmakoterapi dan intervensi psikososial (Amir, 2012; Soetjipto, 2012; Yatham et.al, 2009). Intervensi psikososial yang dapat dilaksanakan pada orang dengan gangguan bipolar yaitu psikoedukasi, cognitivebehavioral therapy (CBT), family-focused therapy (FFT), terapi ritme sosial dan interpersonal.

Intervensi psikososial dibutuhkan oleh orang dengan gangguan bipolar, karena kekambuhan yang terjadi pada penderita bipolar akan mengganggu fungsi sosial, mengganggu pekerjaan, mengganggu perkawinan bahkan meningkatkan risiko bunuh diri. Terkait dengan kondisi tersebut, 
pekerjaan sosial dapat mengambil bagian dalam penanganan penderita gangguan bipolar. Intervensi yang dilakukan oleh pekerja sosial dapat dengan memberikan dukungan kepada individu dan keluarga, di samping pengobatan atau perawatan medis lainnya tetap dijalankan. Sejalan dengan hal tersebut, Smith (2011: 341) memaparkan bahwa:

"Pekerja sosial sering menyediakan layanan, pertemuan dengan klien secara teratur untuk membantu mereka dalam mengurangi gejala, meningkatkan koping, dan membantu dengan stres kehidupan. Jika klien adalah anak, pekerja sosial juga mungkin memiliki kontak dengan keluarga, personil sekolah, dan anggota sistem lain yang terlibat dalam kehidupan anak."

Pelaksanaan layanan yang disediakan oleh pekerja sosial ini didasari oleh kebutuhan individu yang tidak hanya seputar pengobatan medis saja, tetapi juga kehidupan sosial dari individu penderitanya. Layanan tersebut tidak hanya ditujukan bagi individu dengan gangguan bipolar saja, tetapi juga dengan melibatkan lingkungan di sekitarnya sebagai sistem sumber yang dimanfaatkan oleh pekerja sosial dalam mengintervensi penderita gangguan bipolar. Seperti yang telah disampaikan sebelumnya bahwa keluarga memiliki peran penting dalam penyembuhan penderitanya, maka pekerja sosial pun turut bekerja dengan keluarga bahkan memberikan dukungan, konseling dan mengintervensinya agar kehadiran keluarga dapat sejalan dengan penyembuhan individu yang mengalami gangguan bipolar. Pekerja sosial juga tentunya bekerja dengan profesi-profesi lainnya yang dibutuhkan dalam menangani penderita gangguan bipolar, seperti dengan tim medis apabila dibutuhkan obat penenang atau mood stabilizer untuk kliennya.

\section{Tinjauan Pustaka \\ Gangguan Bipolar}

Perubahan suasana hati yang dialami oleh penderita gangguan bipolar terjadi secara signifikan, karena perasaan yang berlebihan dan tidak terkendali pada penderitanya. Smith (2011: 332) menyatakan bahwa orang dengan kondisi demikian mungkin mengalami fluktuasi perasaan yang luas dalam suasana hatinya, saat yang sangat 'baik' atau yang sangat 'buruk' dalam diri mereka.

Smith (2011: 333) menyampaikan bahwa individu dengan gangguan bipolar setidaknya mengalami tiga dari gejala-gejala berikut ini, yaitu:

1. Meningkatnya harga diri dan kemegahan adalah fitur umum dari episode manic, seperti penurunan kebutuhan untuk tidur.

2. Berbicara dan proses berpikir bertambah cepat; berbicara dengan kondisi tertekan dan pemikiran yang melompat dengan cepat dari satu topik ke topik yang lainnya.

3. Dapat dengan mudah terganggu atau gelisah. Akhirnya, terjadilah peningkatan aktivitas sosial, seksual, atau pekerjaan, dan terutama keterlibatan dalam kegiatan yang menyenangkan, yang dapat mengakibatkan perilaku sembrono yang memiliki potensi konsekuensi negatif, dan bahwa kemudian individu yang bersangkutan merasakan penyesalan.

Pada penderita gangguan bipolar, perasaan mereka sering berayun dari tingkat rendah, yaitu depresi kemudian berubah ke atas, menjadi mania. Ketika berada pada tingkat depresi, penderita bipolar akan merasa sedih tidak berdaya serta merasa putus asa. Sebaliknya, ketika pada tingkat mania, penderita bipolar akan terlihat riang gembira dan penuh energi (Jiwo, 2012: 2). Secara rinci Jiwo (2012: 3) memaparkan beberapa gejala yang muncul pada saat penderita gangguan bipolar berada dalam kondisi mania, yaitu: euphoria (gembira), inflated self-esteem (percaya diri berlebihan), poor judgment (kemampuan menilai menjadi jelek), bicara cepat, racing thoughts (pikiran saling berkejarkejaran), aggressive behavior (perilaku agresif), agitation or irritation (agitasi atau iritasi), kegiatan fisik meningkat, risky 
behavior (perilaku yang berbahaya), spending sprees or unwise financial choices (tidak mampu mengelola uang, mengeluarkan uang tanpa perhitungan), meningkatkan dorongan untuk berprestasi atau mencapai tujuan, meningkatnya dorongan seksual, berkurangnya dorongan untuk tidur, tidak merasa mengantuk, gampang terganggu konsektrasi, berlebihan dalam mengkonsumsi alcohol atau obat-obatan, sering bolos sekolah atau kerja, mempunyai waham atau keluar dari realitas, prestasi kerja atau sekolah menurun.

Adapun pada kondisi depresi, gejala yang muncul antara lain: kesedihan, merasa tanpa harapan, keinginan atau tindakan bunuh diri, anxiety (kecemasan), perasaan bersalah, gangguan tidur, nafsu makan menurun atau bahkan naik, merasa lelah berlebihan, hilangnya minat pada kegiatan yang dulu dinilainya menarik/menyenangkah, sulit berkonsentrasi, mudah tersinggung, rasa nyeri kronis tanpa alasan yang jelas, sering mengkir sekolah/kerja, prestasi rendah di sekolah atau tempat kerja (Jiwo, 2012: 3-4).

Mengenai penyebab gangguan bipolar, Barbara dan Sam (dalam Putra, 2014: 5) menyebutkan bahwa:

"Gangguan jiwa bipolar adalah penyakit gangguan jiwa yang bukan disebabkan tekanan psikologis, melainkan karena terjadinya gangguan keseimbangan pada otak. Bipolar terjadi secara biologis berupa gangguan di neurotransmitter otak yang berfungsi mengatur keseimbangan. Faktor genetika dianggap sebagai mekanisme gen yang saling bergantung, sedangkan aktivitas dalam kehidupan sehari-hari di lingkungan sekitar merupakan faktor dari segi psikososial biasanya mendahului episode awal dari gangguan bipolar. Ada 10-12\% kasus pada gangguan jiwa bipolar yang semakin memburuk setelah mengkonsumsi NAPZA."

Gangguan bipolar menurut DSM-V terdiri dari dua bagian, yaitu Bipolar I dan Bipolar II. Antara gangguan Bipolar I dan
Bipolar II, terdapat perbedaan periode atau episode munculnya mood baik dan mood buruk pada penderitanya. Menurut Smith (2011: 332), gangguan Bipolar I didefinisikan oleh kehadiran setidaknya satu episode manic atau campuran. Sebuah episode manik adalah periode minimal satu minggu di mana suasana hati individu adalah luar biasa tinggi, ekspansif, atau mudah tersinggung. Berdasarkan pendefinisian tersebut, terjadinya kondisi pada peningkatan aktivitas sosial, seksual, atau pekerjaan, dan terutama keterlibatan dalam kegiatan yang menyenangkan bahkan memiliki potensi yang berbahaya bagi pada penderitanya. Ketika dalam kondisi mania, penderitanya sering berada dalam kondisi "berat" dan berbahaya. Kondisi suasana hati pada individu yang dapat berfluktuasi cepat dari kesedihan ke euforia kegembiraan yang berdampak pada gangguan fungsi dan potensi konsekuensi negatif.

Pada gangguan Bipolar II, Smith (2011: 333) berpendapat mengenai hal itu bahwa gangguan Bipolar II mirip dengan gangguan bipolar, tetapi membutuhkan kehadiran setidaknya satu episode depresi, serta episode hypomanic. Sebuah episode hypomanic seperti episode manik, tapi lebih pendek dan tidak cukup parah untuk mengganggu fungsi atau memerlukan rawat inap. Pada gangguan Bipolar II, kondisi suasana hati penderitanya tidak seberat pada Bipolar I, sehingga penderitanya masih dapat melaksanakan fungsi dan aktivitas harian. Pada episode hypomanic, penderitanya terlihat lebih bahagia dalam kondisi tenang, tetapi juga mudah tersinggung. Ketika suasana hatinya sedang "naik" atau menjadi tinggi, penderita hanya mencapai tingkat hypomanic, dan kondisi hypomanic ini cenderung berlangsung tidak begitu lama jika dibandingkan dengan kondisi pada episode depresi.

Gangguan bipolar tidak hanya diderita oleh orang dewasa saja, tetapi juga bisa dialami oleh anak-anak. Smith (2011: 336) dalam bukunya menyebutkan bahwa ada satu teori yang menunjukkan bahwa masalah pada anak-anak sering kompleks dan beragam, dan bahwa gejala yang terkait dengan kondisi 
bipolar pada anak-anak mungkin sebenarnya disebabkan oleh dinamika keluarga yang mengalami masa sulit, termasuk penyalahgunaan atau kelalaian. Menurut Smith (2011: 336), masalah yang terjadi mengenai kondisi bipolar pada anak-anak ini tidak identik dengan yang dialami oleh orang dewasa, namun tetap menunjukkan adanya suasana hati yang labil, gangguan psikososial, mudah tersinggung, gejala mania (gembira berlebih) dan tampaknya juga berbeda dengan orang dewasa. Pada penanganannya, intervensi yang dilakukan pada anak-anak juga didasarkan pada pelayanan kesehatan mental, tetapi penggunaan obat yang diberikan pada anak-anak harus dengan hati-hati, sebab obat tersebut dapat memiliki dampat jangka panjang pada fungsi neurobiologis mereka.

Di antara anak-anak dengan gangguan bipolar yang menerima rawat jalan pelayanan kesehatan jiwa, banyak diantara mereka yang tidak menerima layanan terapi keluarga, yang merupakan komponen penting dari proses pelayanan (Rizzo et al., 2007). Orang tua dari anak-anak dengan bipolar menghadapi beberapa hambatan untuk mendapatkan pengobatan, termasuk kurangnya penyedia layanan pengetahuan tentang bipolar, komunikasi yang buruk dengan penyedia layanan dan kecenderungan penyedia layanan yang menyalahkan orang tua terkait dengan kondisi anak dengan bipolar (MackinawKoons \& Fristad, 2004).

Orang dewasa yang lebih tua dengan kondisi bipolar cenderung sedikit menggunakan layanan kesehatan mental (Sajatovic, 2002) ataupun menggunakan layanan jasa kejiwaan yang sangat akut (Depp et al., 2005). Namun demikian, orang dewasa yang lebih tua dengan depresi unipolar lebih banyak menggunakan layanan kesehatan mental dan lebih mungkin untuk mendapatkan layanan psychiatrically rumah sakit (Bartels, Forester, Miles, \& Joyce, 2000).

\section{Pekerjaan Sosial dengan Penderita Gangguan Bipolar}

Dalam konteks kesehatan mental, profesi pekerjaan sosial dapat berperan serta memberikan pelayanan. Pengobatan yang diberikan pada penderita gangguan bipolar pun berada dalam sistem pelayanan kesehatan mental. Smith (2011: 341) mengungkapkan bahwa, pengobatan yang diberikan pada penderita gangguan bipolar setidaknya berada pada tingkat batasan perawatan layanan rawat jalan, di mana klien berada di klinik untuk terapi dan mungkin untuk mendapatkan layanan pemberian obat. Klinik yang memberikan layanan bagi orang dengan gangguan bipolar dapat berbasis rumah sakit, organisasi berbasis masyarakat, atau pun setting lainnya seperti sekolah.

Pada penanganan penderita gangguan bipolar, adapun intervensi yang dilakukan pada pekerjaan sosial seperti yang disampaikan oleh Smith (2011: 341), bahwa:

"Pekerja sosial sering menyediakan layanan, pertemuan dengan klien secara teratur untuk membantu mereka dalam mengurangi gejala, meningkatkan koping, dan membantu dalam mengatasi stres kehidupan. Jika klien adalah anak, pekerja sosial juga mungkin memiliki kontak dengan keluarga, personil sekolah, dan anggota sistem lain yang terlibat dalam kehidupan anak."

Layanan yang diberikan oleh pekerja sosial terhadap penderita gangguan bipolar adalah melalui pertemuan-pertemuan rutin ini dilakukan untuk membantu mengurangi gejala, meningkatkan koping dan membantunya menghadapi stress dalam kehidupan. Kekambuhan yang terjadi pada diri penderita memang membutuhkan layanan medis, seperti pengobatan, namun peran pekerja sosial untuk dapat mengintervensi penderita gangguan bipolar juga menjadi hal yang penting. Pekerja sosial bekerja dengan memanfaatkan lingkungan sekitar di mana penderita berada, seperti lingkungan keluarga, orang-orang yang turut dilibatkan dalam proses penyembuhan, bahkan sistem sumber lain yang memungkinkan efektivitas pelaksanaan intervensi agar penderita tetap dapat berfungsi secara sosial dalam hidupnya. 
Para pekerja sosial juga dapat membuat kelompok maupun bekerja secara individual dengan klien. Pemanfaatan kelompok sebagai metode intervensi yang dilakukan pekerja sosial agar individu yang menderita gangguan bipolar dapat hadir di tengah-tengah kelompok dengan diberi tugas seiring dengan pelaksanaan program kesehatan mentalnya dalam jangak atau periode waktu tertentu. Pekerja sosial juga tetap melibatkan keluarga, penyedia rawat jalan, dan pihak terkait lainnya dalam pelaksanaan intervensi ini.

Sejalan dengan intervensi yang dilaksanakan terhadap klien, pekerja sosial juga perlu terus memantau kondisi yang dialami oleh klien, termasuk keinginan bunuh diri yang sering kali muncul pada penderita gangguan bipolar karena meningkatnya kondisi depresi. Apabila dibutuhkan rawat inap di klinik atau rumah sakit, pekerja sosial perlu merujuk penderita agar dapat mengendalikan gejolak perubahan kondisi suasana hatinya. Kebutuhan rawat inap karena psikosis yang kadang menyertai episode manic juga perlu diperhatikan oleh pekerja sosial.

Menurut Smith (2011: 342), program rawat inap cenderung dilakukan dalam jangka waktu yang sangat pendek, hitungan hari atau mungkin minggu, dan dirancang untuk menstabilkan klien melalui proses penilaian secara hati-hati, manajemen obat, dan proses perencanaan untuk pulang.

Pekerja sosial dalam pengaturan rawat inap berfungsi sebagai bagian dari tim interdisipliner yang mungkin termasuk di dalamnya adalah profesi psikiater, perawat, psikolog, dan paraprofessional. Mereka umumnya bertanggung jawab untuk koordinasi perawatan dan perencanaan terkait dengan beban kasus mereka.

Lebih lanjut disampaikan oleh Gitterman dan Germain (dalam Smith 2011: 342), pada setiap tingkat perawatan, pekerja sosial bekerja secara langsung dengan klien dan keluarga mereka, memberikan konseling individu dan kelompok. Konsisten dengan pendekatan pekerjaan sosial yang berfokus pada klien dengan lingkungannya. Menurut Gitterman dan Germain (dalam Smith 2011:
342), peran pekerja sosial juga cenderung untuk mengkoordinasikan berbagai sistem yang mungkin terlibat dalam kehidupan klien. Pekerja sosial bekerja untuk memobilisasi sistem dan membuat jaringan dukungan untuk klien yang akan membantu klien untuk mengatasi tantangan hidup dengan kondisi bipolar.

Pada konteks pekerjaan sosial, intervensi lainnya dapat dilakukan dengan pendekatan yang disebut model perawatan kolaboratif. Morris, Miklowitz, dan Waxmonsky (dalam Smith, 2011: 342), menyampaikan bahwa adanya pendekatan yang disebut model perawatan kolaboratif yang bertujuan untuk melibatkan klien dalam perawatan diri mereka sendiri, melibatkan klien dan keluarga dalam perencanaan perawatan dan memberi mereka keterampilan untuk mengelola penyakit. Berdasarkan pernyataan tersebut, menjelaskan bahwa model ini jelas konsisten dengan pendekatan pekerjaan sosial dalam pemberdayaan klien dan penentuan nasib sendiri.

Dalam menjalankan tugasnya, pekerja sosial turut berkolaborasi di antara penyedia layanan kesehatan bagi penderita gangguan bipolar. Individu dengan gangguan bipolar mungkin telah mengakses beberapa penyedia layanan kesehatan, baik itu di bidang kesehatan medis maupun kesehatan mental dan mungkin pada tingkat layanan yang berbeda dari perawatan tersebut. Dalam situasi seperti ini, pekerja sosial dapat melakukan koordinasi dengan berbagai pihak yang terlibat. Menurut William dan Manning (dalam Smith, 2011: 342), koordinasi antara berbagai penyedia layanan bagi klien dengan gangguan bipolar telah terbukti meningkatkan kesehatan klien, baik itu kesehatan medis maupun kesehatan mental. Ada pun tujuan dari model perawatan kolaboratif adalah untuk meningkatkan akses klien untuk memperoleh layanan perawatan, kesinambungan perawatan, dan aliran informasi antara berbagai pihak yang terlibat dalam perawatan klien (Bauer et al., 2006a). 


\section{Metode}

Metode yang digunakan adalah studi literature, yakni dengan melakukan mengumpulkan dan pengkajian data baik dari buku, jurnal, maupun website (internet) yang berkaitan dengan topik yang diteliti, yakni pekerjaan sosial dan orang dengan gangguan bipolar.

\section{Pembahasan}

Gangguan bipolar merupakan salah satu bentuk mood disorder, di mana penderitanya mengalami perubahan kondisi mood secara signifikan dan esktrem. Penderita gangguan bipolar umumnya memiliki dua kutub emosi, yaitu gembira dan sedih yang berada pada kadar batas atau kewajaran. Mereka mengalami fluktuasi suasana perasaan pada kondisi yang sangat baik ataupun sangat buruk. Kedua kondisi yang berbeda itu disebut juga dengan kondisi mania/manic (bahagia) dan kondisi depresi (sedih).

Berada di tengah lingkungan keluarga atau masyarakat merupakan hal yang dihadapi oleh seorang penderita gangguan bipolar. Keluarga memiliki peran penting untuk mendeteksi gejala yang timbul dari anggota keluarga yang mengalami kondisi bipolar. Fluktuasi perasaan yang dialami oleh penderita dapat terjadi karena berbagai faktor yang mempengaruhinya, karena itu dukungan keluarga dibutuhkan untuk dengan tanggap membantu penanganan penderita bipolar. Walaupun demikian, pengobatan bagi penderita bipolar memang dibutuhkan, hal ini agar secara kesehatan melalui konsumsi obat yang sesuai dapat menstabilkan kembali kondisi suasana hati penderitanya.

Pekerja sosial dituntut untuk perlu melihat kembali bagaimana hak-hak kliennya dan kesadaran sumber daya yang tersedia pada organisasi kesehatan mental. Rumusan atau perencanaan yang dilakukan oleh pekerja sosial bertujuan untuk mengakomodasi kebutuhan klien. Pada masa pengobatannya, klien menerima proses stabilisasi melalui ragam obat: obat untuk berpikir teratur, untuk depresi, untuk stabilisasi suasana hati, dan untuk kecemasan, yang membuatnya berangsur stabil hingga tim pengobatan merekomendasikan perencanaan pulangnya. Pekerja sosial terus melihat dan memantau kondisi klien dan tetap memastikan klien dapat mampu berinteraksi dengan orang lain.

Intervensi praktik pekerjaan sosial bervariasi, sesuai dengan kebutuhan klien. Sepanjang sejarah praktik pekerjaan sosial dalam sistem kesehatan dan kesehatan mental, pekerja sosial secara konsisten bekerja sebagai advokat dan manajer kasus, yang dapat dijelaskan sebagai berikut:

1. Advokasi meliputi advokasi kasus, di mana seorang pekerja sosial membantu klien untuk memenuhi kebutuhan spesifik. Hal ini juga termasuk penyebab atau kelas advokasi, di mana kebutuhan yang tidak terpenuhi dikelompokkan dan disusun dalam kegiatan advokasi.

2. Manajemen kasus. Tugas dari manajer kasus adalah: bekerja dengan klien dalam mengidentifikasi jenis bantuan yang dibutuhkan, mengidentifikasi dan mengatasi hambatan dalam menggunakan layanan, membantu secara efektif (bentuk advokasi), memberikan layanan secara langsung dalam mengatasi hambatan, menghubungkan klien dengan pembantu potensial, menyediakan layanan koordinasi dan mempertahankan hubungan ini sampai masalah diselesaikan.

Salah satu layanan yang dilakukan oleh pekerja sosial adalah layanan manajemen kasus, bekerja sama dengan sistem pelayanan kesehatan, ruang rawat inap negara dapat diberikan kepada klien yang telah dibayarkan oleh negara. Hal ini dilakukan oleh pekerja sosial agar klien tetap memperoleh hak untuk mendapatkan tempat tinggal yang layak.

Melalui layanan manajemen kasus, pekerja sosial juga perlu memastikan kehidupan klien dalam membantunya untuk dapat mengakses layanan yang dibutuhkan, baik itu dengan psikiater maupun perawat, serta dalam upaya memecahkan masalah yang dihadapinya, dan membantu klien agar terus 
bersedia menerima kebutuhannya berupa obatobatan stabilisasi tanpa paksaan. Berdasarkan pemaparan manajemen kasus tersebut, pekerja sosial dalam kaitannya dengan penanganan penderita gangguan bipolar memiliki tugas untuk menyeimbangkan kebutuhan klien dan layanan akses untuk memenuhi kebutuhan hidupnya.

\section{Simpulan}

Orang dengan gangguan bipolar yang mengalami perubahan suasana hati yang ekstrem, saat yang sangat baik atau disebut juga mania dan saat yang sangat buruk atau disebut juga depresi. Kedua bentuk tersebut terjadi secara berlebihan pada diri penderita bipolar. Pada saat fase mania, penderita akan mengalami gairah yang berlebih, baik dalam melakukan kegiatan yang menyenangkan, hubungan seksual, maupun dalam berhadapan dengan orang-orang di sekitarnya. Pada saat fase depresi, penderita akan mengalami keputus-asaan, merasa tidak berdaya, mudah marah dan tersinggung, bahkan dapat memunculkan keinginan untuk bunuh diri. Berbagai faktor yang melatarbelakangi gangguan ini, seperti faktor genetika, biologis, maupun lingkungan, sehingga mempengaruhi kondisi bipolar yang terjadi pada seorang individu.

Penderita gangguan bipolar yang berada di tengah-tengah masyarakat ini membutuhkan penanganan agar mampu hidup bersama selayaknya seperti orang pada umumnya. Penanganan yang diberikan, baik oleh tim pengobatan seperti psikiater, perawat, maupun pekerja sosial. Pada konteks pekerjaan sosial, profesi pekerja sosial memberikan pelayanan berupa dukungan kepada individu yang menderita gangguan bipolar serta dukungan kepada keluarga yang dapat membantu keberlangsungan proses penyembuhannya. Pekerja sosial juga dapat memberikan layanan berupa pertemuan rutin, baik untuk melakukan konseling maupun pemecahan masalah dan gejala kekambuhannya, dan melalui penugasan dalam kelompok bagi penderita bipolar, layanan manajemen kasus untuk mengakomodasi kebutuhan dan bantuan klien, bahkan memberikan layanan dukungan kepada keluarga untuk membantu mereka pada masamasa penyembuhannya.

\section{Daftar Pustaka}

Amir N. (2012). Tata Laksana Gangguan Bipolar, Episode Manik, Fase Akut. Dalam: Kumpulan Makalah Konferensi Nasional I Gangguan Bipolar. Surabaya: Airlangga University Press. Hal 1-6

Evans D. L. (2000). Bipolar Disorder: Diagnostic Challenges and Treatment Considerations. J. Clin Psychiatry 2000; 61(suppl 13); 26-31. Diunduh dari http://altcancerweb.com/bipolar/tratmentguide lines/treatmenyguidelines-bipolar-states2000.pdf

Kartika, Unoviana. (2014). Pengobatan yang Tepat untuk Gangguan Bipolar. http://health.kompas.com/read/2014/08/19/13 4959523/Pengobatan.yang.Tepat.untuk.Gang guan.Bipolar. Diunduh pada tanggal 21 Desember 2015 pukul 19:21 WIB.

Jiwo, Tirto. (2012). Mengenal Gangguan Bipolar: Panduan bagi anggota keluarga, relawan kesehatan jiwa dan perawat pendamping. Jawa Tengah: Pusat Pemulihan dan Pelatihan Bagi Penderita Gangguan Jiwa.

Lowe \& Cohen. (2010). Living with Someone Who's Living with Bipolar Disorder. San Fransisco: Jossey-Bass.

Putra, Hendrikus Gede Surya Adhi. (2014). Gangguang Afektif Bipolar Mania dengan Psikotik: Sebuah Laporan Kasus. http://ojs.unud.ac.id/index.php/eum/article/do wnload/8514/6375. Diunduh pada tanggal 21 Desember 2015 pukul 20:17 WIB.

Raharjo, ST (ed). (2016). Kerentanan dan Disabilitas, Kumpulan Tulisan. Bandung: Unpad Press. 


\begin{tabular}{|c|c|c|c|c|}
\hline $\begin{array}{c}\text { Jurnal Penelitian \& } \\
\text { PPM }\end{array}$ & ISSN: 2442-448X & Vol 5, No: 1 & Hal: $1-110$ & April 2018 \\
\hline
\end{tabular}

Raharjo, ST .(2015). Pekerjaan Sosial Generalis, Pengantar Bekerja Bersama Organisasi dan Komunitas. Bandung: Unpad Press.

Ryan \& Jacki (Ed). (2004). Good Practice in Adult Mental Health. London: Jessica Kingsley Publisher.

Samosir, Hanna Azarya. (2015). 10-15 Persen Nyawa Pengidap Bipolar Habis di Tangan Sendiri. http://www.cnnindonesia.com/gayahidup/20150819160449-255-73166/10-15persen-nyawa-pengidap-bipolar-habis-ditangan-sendiri. Diunduh pada tanggal 21 Desember 2015 pukul 17:50 WIB

Smith, Ellen. (2011). "Mood Conditions" dalam Hiller dan Gitterman (Eds.) Mental Health and Social Problems: A Social Work Perspective. London: Routledge.

Soetjipto. (2012). Terapi Rumatan Pada Pasien Gangguan Bipolar. Dalam: Kumpulan Makalah Konferensi Nasional I Gangguan Bipolar. Surabaya: Airlangga University Press. Hal 14-22
Tohen M dan Angst J. (2002). Epidemiology of Bipolar Disorder. In M.T. Tsuang \& Tohen M. (Eds), Textbook in Psychiatric Epidemiology second edition (pp. 427-447). New Jersey: John Wiley \& Sons, Inc.

Toni C., Perugi G., Mata B., Madaro D., Maremmani I., Akiskal H., S. (2000). Is mood-incongruent manic psychosis a distinct subtype? Eur arch psychiatry Clin Neurosci (2001) 251: 12-17. Diunduh dari http://msrc.fsv.edu/system/files/TonieCetal20 01ismoodincongruentmanicpsychosisadistinctsubtype

Wibhawa, B., Raharjo, ST., \& Santoso, MB. 2010. Dasar Dasar Pekerjaan Sosial. Widya Padjadjaran: Bandung

Yatham L. N., Kennedy S. H., Schaffer A., Parikh S. V., Beauliu S., O’Donovan C., McQueen G., McIntyre R. S., Sharma V., Ravindran, Young L. T., Young A. H., Alda M., Milev R., Vieta E., Calebrese J. R., Berk M., Ha K., Kapczinski F. (2009). Canadian Network for Mood and Anxiety Treatment (CANMAT) and International Society for Bipolar Disorder collaborative update of CANMAT guidelines for management of patient with bipolar disorder: update 2009. Bipolar Disord. May; 11: 225-255. 